\title{
Vapour-Liquid Equilibria of Ethane and Ethanethiol: Experiments and Modelling
}

\author{
Waheed Afzal ${ }^{1,2 *}$, Alain Valtz ${ }^{3}$ and Christophe Coquelet ${ }^{3}$ \\ ${ }^{1}$ Chemical and Materials Engineering, School of Engineering, University of Aberdeen, Aberdeen \\ AB24 3NY, Scotland, the United Kingdom \\ ${ }^{2}$ Institute of Chemical Engineering E Technology, University of the Punjab, Lahore 54590, \\ Pakistan \\ ${ }^{3}$ MINES ParisTech, PSL University, Centre Thermodynamique des Procédés, \\ Fontainebleau 77300, France
}

Received July 17, 2018; Accepted October 1, 2018

\begin{abstract}
This work reports high-quality isothermal vapor-liquid equilibrium data for ethane + ethanethiol (or ethyl mercaptan) at $303 \mathrm{~K}, 323 \mathrm{~K}$ and $343 \mathrm{~K}$ and pressures up to $6.25 \mathrm{MPa}$. A sapphire-tube equilibrium cell with an online micro sampler and GC-TCD are employed to measure equilibrium phase concentrations at specific temperatures and pressures. Peng Robinson equation of state with classical alpha function is found adequate for data treatment and thermodynamic modelling.
\end{abstract}

Keywords: VLE data, Peng Robinson EoS, NRTL model, sulphur species, alkanethiol, alkanes, nature gas

\section{Introduction}

Worldwide total energy requirements are increasing whereas fossil resources are depleting. With the pressure of producing and processing more oil and gas, unique challenges are arising from processing and environmental protection point of view. One particular challenge concerns the presence of significant quantities of sulphur compounds in the produced oil and gas resources. The distribution of organic sulphur compounds such as mercaptans is a major concerns for the processing equipment and the products [1]. Measurement of reliable thermodynamic data is also a significant endeavour because of its wide applications in the broader areas of science, technology and environment [1-3].

*Corresponding author: Waheed@abdn.ac.uk

DOI: 10.7569/JNGE.2018.692505 
Because all of these sulphur compounds are highly toxic and volatile, it's very difficult to obtain reliable thermodynamic data: solubilities or gas-liquid equilibria (GLE), vapour-liquid equilibria (VLE), liquid-liquid equilibria (LLE), physical properties, etc. Centre Thermodynamique des Proécdés at MINES ParisTech in Fontainebleau is one of the few places where highly toxic and difficult to measure systems can be studied to produce reliable data. We have reported numerous studies $[1,2,4-10]$ with reliable thermodynamic data on sulphur species in the context of oil and gas systems. Gas Processors Association has commissioned several earlier studies to provide reliable thermodynamic data to its members; for example GPA research report RR-228 presents sulphur species distribution in selected natural gas systems, however their studies are usually restricted to GPA membership. Our study provides isothermal VLE data for (ethane + mercaptan) binary system at $303 \mathrm{~K}, 323 \mathrm{~K}$ and $343 \mathrm{~K}$ and pressures up to $6.25 \mathrm{MPa}$.

Production of hydrocarbons having significant quantities of sulphur species were considered uneconomically in the past. However, with the demand and developments in gas engineering practices, exploitation of high-sulphur reserves is often viable. The global production of sour natural gases is on rise in several countries; Canada is the second largest producer of natural gas in the western hemisphere after the United States, having 57.9 trillion SCF of proven natural gas reserves as in 2009. About 30 percent of total natural gas production of Canada is sour with an average of about 10 percent sulphur species ranging from traces to about 80 percent of well head gases. Canada is producing about one quarter of all elemental sulphur being the largest sulphur producing country of the world [1,4].

Strong desire and stringent legislations for environmental protection are forcing the hydrocarbon industry to develop more efficient practices either by improving existing processes or developing new ways. The engineering solutions require the reliable phase equilibrium information of systems involving hydrocarbons and sulphur compounds in order to develop and extend thermodynamic models. These models can be used for process design and optimization.

The current study reports isothermal VLE data from $303 \mathrm{~K}$ to $343 \mathrm{~K}$ and from 0.97 MPa to 6.25 MPa. Experimental data are measured using a well-documented high-pressure static view cell equipped with an online micro-sampler and a GC-TCD [1, 4, 6]. Peng Robinson equation of state with classical alpha function [11, 12] and NRTL activity coefficient model [13] are used for thermodynamic modelling with success [11].

\section{Experimental Section}

The experiments used research grade chemicals listed in Table 1. Liquid was degassed in-situ in the equilibrium cell which was added first and then ethane gas was loaded. Table 2 shows the list of chemicals used in this work along with their minimum purity and suppliers; no further purification of the products was required. 
Table 1 Global experimental uncertainties on VLE data.

\begin{tabular}{|l|l|l|}
\hline Measurement/Sensor & Uncertainty & Remarks \\
\hline Pressure & $< \pm 1 \mathrm{kPa}$ & Druck pressure transducers \\
Temperature & $\leq \pm 0.02 \mathrm{~K}$ & Pt. $100 \Omega$ sensors \\
GC for ethane & $< \pm 0.25 \%$ & TCD calibration with a gas-tight syringe \\
TCD for ethyl mercaptan & $\leq \pm 0.5 \%$ & TCD calibration with a liquid syringe \\
Compositions $(x, y)$ & $< \pm 0.5 \%$ & with plunger \\
& & TCD calibration with standard syringes \\
\hline
\end{tabular}

Table 2 Purities and suppliers of the chemicals used in this work.

\begin{tabular}{|l|l|l|}
\hline Chemicals & Purity (GC) & Supplier \\
\hline Ethane & 99.9 vol\% & Air Liquide \\
\hline Ethylmercaptan & $\geq 99$ vol\% & Sigma Aldrich \\
\hline
\end{tabular}

The experimental setup used for VLE measurements involving sulphur species and hydrocarbons is based on analytic-static technique with a local phase agitator to facilitate fast equilibration; it is explained by our earlier work [1]. In summary, the equilibrium cell consists of a sapphire tube, held between two stainless steel flanges with suitable o-rings. Each flange contained valves for loading and cleaning the cell. A vertical multiple phase magnetic agitator is installed in the centre of the sapphire tube for both phases. The stirring assembly is protected with a suitable corrosion resistant cover to withstand for corrosive environment. The agitation assembly is magnetically coupled to an external agitation motor, which is capable of producing desired level of agitation inside the cell.

Two calibrated $100 \Omega$ platinum resistance thermometer sensors (Pt-100) are used to measure equilibrium temperatures at the lower and upper parts of the cell. The temperature measurements at two locations enable to examine and void temperature gradients in the cell. The equilibrium pressures are measured thanks to two calibrated Druck pressure transducers (PTX 611); one for lower and other for higher pressure ranges. Both pressure transducers are maintained at constant temperature (higher than maximum temperature of study) by means of an air thermostat, which is controlled by a PID regulator (WEST instrument, model 6100). The schematic diagram of experimental setup is presented in Figure 1 [1].

The online sampling is carried out for each phase using the online capillary samplers. Two samplers were vertically mounted on the equilibrium cell, one for 


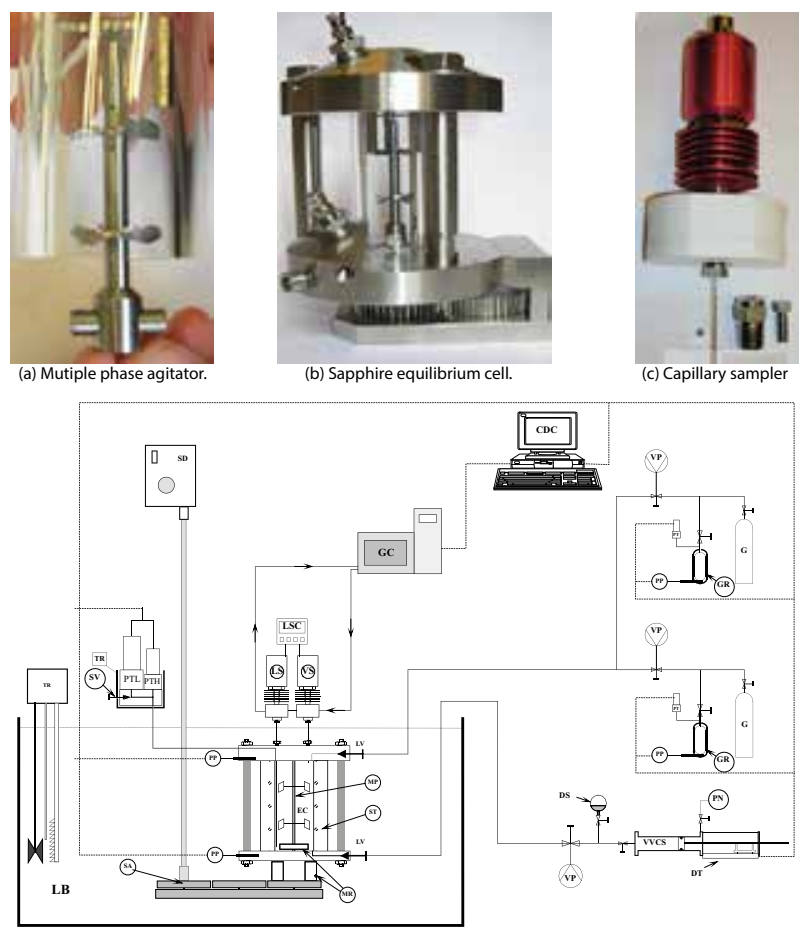

(d) Schematic diagram of the experimental setup using two online samplers.

Figure 1 The experimental setup based on "analytic-static" technique for VLE studies with two online capillary samplers [1].

Descriptions:- CDC: Central desktop computer, DS: Degassed solution, DT: Displacement transducer, EC: Equilibrium cell, G: Gas cylinder, GC: Gas chromatograph, GR: Gas reserve, LB: Liquid bath, LS: Liquid sampler, LSC: Local sample controller, LV: Loading valve, MR: Magnetic rod, MP: Multiple phase agitator, PN: Pressurized nitrogen, PP: Pt temperature sensor, PT: Pressure transducer (L: Low pressure and H: High pressure), SA: Stirring assembly, SD: Stirring device (motor), ST: Sapphire tube, SV: Separation valve, TR: Temperature controller, VP: Vacuum pump, VS: Vapor sampler, VVCS: Variable volume cell for solution.

liquid phase and the other for vapour phase. Each micro sampler is a compact device without any dead volume which consists of a capillary with internal diameter less than $0.2 \mathrm{~mm}$. The sampler is made from corrosion resistant material and is vertically installed on upper flange of the equilibrium cell. The aperture is controlled by electromagnetic means in order to open and close it for specified and controllable time periods. Both the aperture opening time and its frequency can be controlled by local sampling control (LSC) unit on the setup. Figure 2 shows the cross-sectional view, flow diagram, and various parts of the online capillary sampler used for phase sampling. 


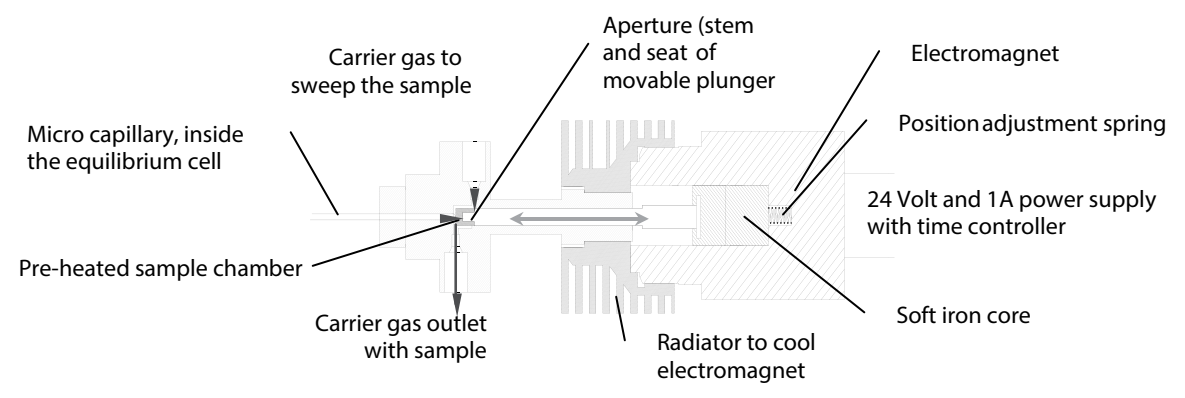

Figure 2 Cross sectional view, flow diagram, and various parts of the online capillary sampler used for phase sampling [1].

The sampling chamber of the online sampler is connected to a GC-TCD through its injector and column in such a way that the carrier gas (Helium) is circulated through the analytical circuit. The sample is transferred from equilibrium cell to the sampling chamber because of positive pressure difference between them. Since the flow rate (and pressure) is kept constant inside the analytical circuit around $300 \mathrm{kPa}$, therefore the minimum pressure requirement inside the equilibrium cell is around 0.5 MPa. The sampling chamber, sample transfer lines and GC injector, all are heated to ensure vaporization of the sample. Because of its universal suitability, a thermal conductivity detector (TCD) is used for analyses. The TCD continuously measures the difference of the thermal conductivity of the carrier gas, passing through the analytical column (containing the sample) and over the TCD filament and thermal conductivity of carrier gas in TCD reference (without any sample). Figure 3 shows the flow circuit and various parts of the analytical loop for online sample analysis using GC. GC was equipped with a 4-meter long packed column Porapack $Q$ column. At equilibrium conditions, each composition was determined 6-8 times for each phases and average values are reported as experimental data at the specific temperatures and pressures; the data are presented in Table 3.

The uncertainties associated with the mole fraction determination are less than $1 \%$ for both species, $0.03 \mathrm{~K}$ for temperature, $0.4 \mathrm{kPa}$ for pressure.

\section{Data Correlation and Results}

The critical temperatures (Tc) and pressures $(\mathrm{Pc})$ and acentric factors $(\omega)$ for pure ethane and Ethylmercaptan are provided in Table 4.

The experimental VLE data of (ethane + Ethylmercaptan) system were correlated using Peng Robinson equation of sate with the classical van der Waals mixing rules (model 1) and with MHV1 mixing rule involving NRTL activity coefficient model (model 2). Original alpha function is considered [14]. In the 


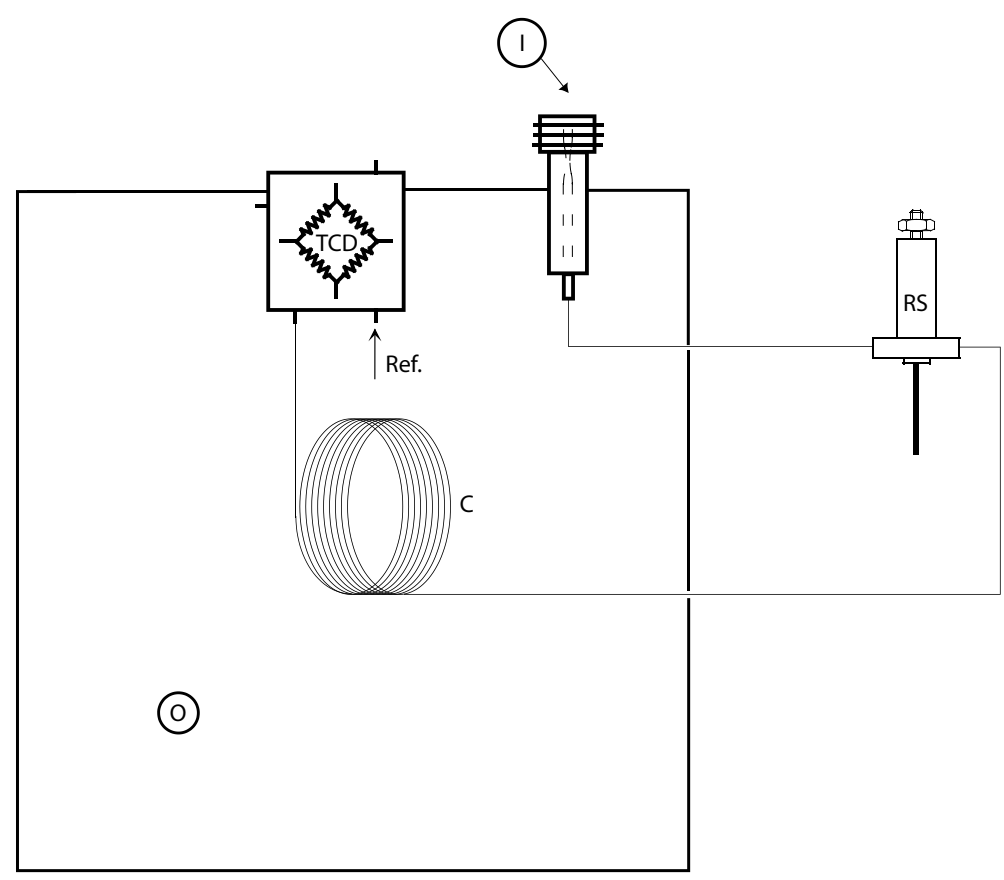

Figure 3 Flow diagram and various parts of the analytical loop for online sample analysis using GC. Description of parts:- C: Analytical pcacked column, I: Injector, O: Oven, RS: Online sampler, TCD: Thermal Conductivity Detector [1].

$\phi-\phi$ approach, we need a mixing rule; $\phi$ is fugacity coefficients. The first mixing rule used to calculate the vapour- liquid equilibrium is the van der Waals mixing rule (Eq. 1).

$$
\begin{aligned}
& a=\sum_{i} \sum_{j} x_{i} x_{j} a_{i j} \\
& b=\sum_{i} x_{i} b_{i}
\end{aligned}
$$

Where $a_{i j}=\sqrt{a_{i} a_{j}}\left(1-k_{i j}\right), \mathrm{k}_{\mathrm{ij}}$ is the binary interaction parameter. The MHV1 (modified Huron-Vidal) mixing rule was proposed by Michelsen [12] where the attractive parameter is calculated by equation 2 .

$$
a=b\left[\sum_{i} x_{i} \frac{a_{i}}{b_{i}}-\frac{R T}{q_{1}} \sum_{i} x_{i} \ln \left(\frac{b_{i}}{b}\right)+\frac{G_{\gamma}^{E}\left(T, P, x_{i}\right)}{q_{1}}\right]
$$


Table 3 Experimental and calculated VLE data of (ethane (1) + ethyl mercaptan (2)) system. $\mathrm{U}(\mathrm{T})=0.03 \mathrm{~K}, \mathrm{U}(\mathrm{P})=0.4 \mathrm{kPa}$ and $\mathrm{u}_{\max }(\mathrm{x}, \mathrm{y})=0.0043$.

\begin{tabular}{|c|c|c|c|c|c|c|}
\hline \multicolumn{3}{|c|}{ Experimental data } & \multicolumn{4}{|c|}{ Calculated data } \\
\hline \multirow[b]{2}{*}{$\mathbf{P}_{\text {exp }} / \mathrm{MPa}$} & \multirow[b]{2}{*}{$\mathbf{x}_{1, \exp }$} & \multirow[b]{2}{*}{$\mathbf{y}_{1, \exp }$} & \multicolumn{2}{|c|}{ Model 1} & \multicolumn{2}{|c|}{ Model 2} \\
\hline & & & $\mathrm{x}_{1, \mathrm{cal}}$ & $\mathbf{y}_{1, \mathrm{cal}}$ & $\mathrm{x}_{1, \mathrm{cal}}$ & $\mathbf{y}_{1, \text { cal }}$ \\
\hline \multicolumn{7}{|l|}{$303 \mathrm{~K}$} \\
\hline 1.056 & 0.133 & 0.887 & 0.135 & 0.910 & 0.143 & 0.911 \\
\hline 1.588 & 0.225 & 0.921 & 0.222 & 0.937 & 0.231 & 0.938 \\
\hline 2.223 & 0.361 & 0.938 & 0.351 & 0.952 & 0.355 & 0.953 \\
\hline 2.762 & 0.507 & 0.940 & 0.497 & 0.959 & 0.490 & 0.960 \\
\hline 3.392 & 0.705 & 0.934 & 0.732 & 0.967 & 0.716 & 0.967 \\
\hline 3.915 & 0.856 & 0.965 & 0.889 & 0.976 & 0.886 & 0.976 \\
\hline \multicolumn{7}{|l|}{$323 \mathrm{~K}$} \\
\hline 5.445 & 0.857 & 0.935 & 0.894 & 0.945 & 0.895 & 0.946 \\
\hline 4.611 & 0.711 & 0.931 & 0.718 & 0.941 & 0.722 & 0.941 \\
\hline 3.977 & 0.574 & 0.932 & 0.565 & 0.936 & 0.567 & 0.936 \\
\hline 3.184 & 0.412 & 0.918 & 0.403 & 0.928 & 0.402 & 0.927 \\
\hline 0.531 & 0.035 & 0.643 & 0.040 & 0.672 & 0.039 & 0.672 \\
\hline 1.320 & 0.123 & 0.839 & 0.132 & 0.857 & 0.130 & 0.857 \\
\hline 2.386 & 0.272 & 0.899 & 0.274 & 0.912 & 0.272 & 0.911 \\
\hline \multicolumn{7}{|l|}{$343 \mathrm{~K}$} \\
\hline 0.707 & 0.034 & 0.495 & 0.039 & 0.557 & 0.028 & 0.554 \\
\hline 1.668 & 0.121 & 0.771 & 0.133 & 0.794 & 0.106 & 0.788 \\
\hline 2.924 & 0.261 & 0.848 & 0.270 & 0.867 & 0.239 & 0.859 \\
\hline 4.195 & 0.419 & 0.877 & 0.430 & 0.892 & 0.428 & 0.884 \\
\hline 4.978 & 0.538 & 0.886 & 0.546 & 0.898 & 0.567 & 0.891 \\
\hline 6.254 & 0.879 & 0.876 & 0.771 & 0.893 & 0.795 & 0.886 \\
\hline
\end{tabular}

Each composition is sampled 8 times to determine liquid and vapour phase compositions; the relative standard deviation is often less than $1 \%$.

Table 4 Thermal properties for ethane and Ethylmercaptan pure component (Source Simulis ${ }^{\mathrm{TM}}$ Thermodynamics).

\begin{tabular}{|l|c|c|c|}
\hline Component & $\mathbf{T}_{\mathbf{c}} / \mathbf{K}$ & $\mathbf{P}_{\mathbf{c}} / \mathbf{M P a}$ & Acentric factor $\omega$ \\
\hline Ethane & 305.32 & 4.872 & 0.099493 \\
\hline EthylMercaptan & 499.15 & 5.490 & 0.187751 \\
\hline
\end{tabular}


The reference pressure is $\mathrm{P}=0$ and molar co-volume $(\mathrm{b})$ is calculate like Van der Waals mixing rule Eq (1). Michelsen recommends a value of $\mathrm{q}_{1}=-0.53$.

The excess Helmholtz free energy is calculated by the NRTL [13] activity coefficient model (Eq. 3).

$$
\frac{G_{\gamma(T, P)}^{E}}{R T}=\sum_{i} x_{i} \sum_{j} \frac{x_{j} \operatorname{Exp}\left(-a_{j, i} \frac{\tau_{j, i}}{R T}\right)}{\sum_{k} x_{k} \operatorname{Exp}\left(-a_{k, i} \frac{\tau_{k, i}}{R T}\right)} \tau_{j, i}
$$

And $\tau_{i, i}=0$ and $\alpha_{i, i}=0$. The adjustable parameters are $a_{j, i^{\prime}} \tau_{j, i}$ and $\tau_{i, j}$. But with our system the recommended value of $a_{j, i}$ is 0.3 .

Binary interaction parameter of these two models were adjusted on experimental data considering the objective function as follows:

$$
\mathrm{F}=\frac{100}{N}\left[\sum_{1}^{N}\left(x_{\exp }-x_{c a l}\right)^{2}+\sum_{1}^{N}\left(y_{\exp }-y_{c a l}\right)^{2}\right]
$$

Tables 5 and 6 present the values of the binary interaction parameters for the two models used for the data treatment and the values of the objective function (Eq 4).

In Figure 4, we present the experimental data and modelling results for PR EoS (model 1); it is obvious that agreement between calculations and experimental

Table 5 Adjusted $\mathrm{k}_{\mathrm{ij}}$ and objective function values for model 1 .

\begin{tabular}{|l|c|c|}
\hline $\mathbf{T} / \mathbf{K}$ & $\mathbf{k}_{\mathrm{ij}}$ & $\mathbf{F}$ (Eq. 4) \\
\hline 303 & 0.0696 & 0.009 \\
\hline 323 & 0.0627 & 0.007 \\
\hline 343 & 0.0553 & 0.035 \\
\hline
\end{tabular}

Table 6 Adjusted NRTL binary interaction parameters and objective function values for model 2.

\begin{tabular}{|l|l|l|l|}
\hline $\mathbf{T} / \mathbf{K}$ & $\tau_{i j} /$ cal.mole $^{-1}$ & $\tau_{i /}$ cal.mole $^{-1}$ & F (Eq. 4) \\
\hline 303 & 843 & -241 & 0.008 \\
\hline 323 & 580 & -106 & 0.007 \\
\hline 343 & -87 & 611 & 0.026 \\
\hline
\end{tabular}




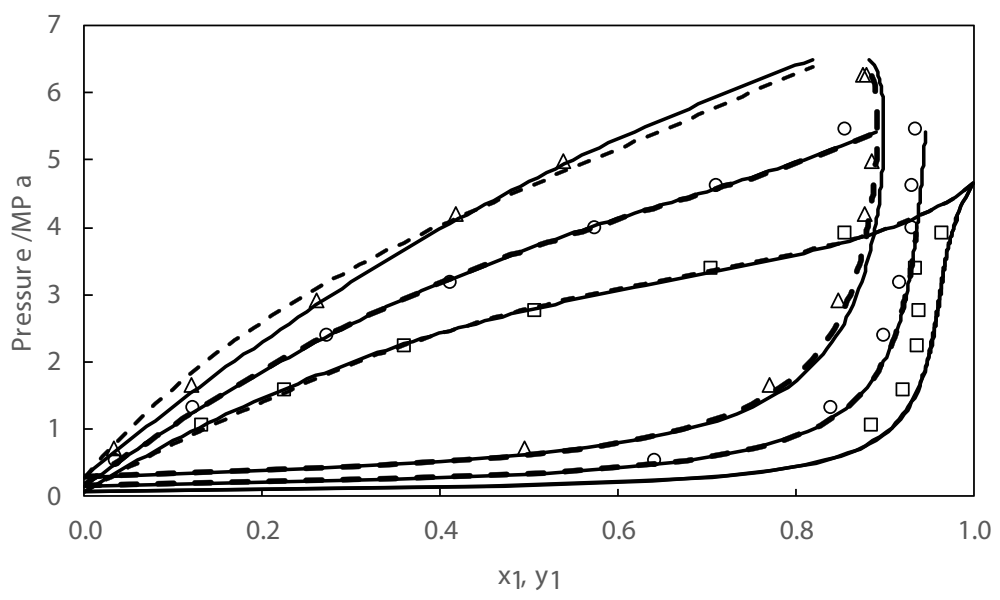

Figure 4 Experimental VLE data, $x_{1}=$ liquid-phase mole fraction of ethane and $y_{1}=$ vapourphase mole fraction, for (ethane + ethyl mercaptan) system. Points are experimental data at three isotherms: $\square 303 \mathrm{~K}$; $\circ 323 ; \Delta 343 \mathrm{~K}$. Solid Lines are calculations using Model 1, dashed lines are calculations using Model 2.

data is acceptable for the VLE of the studied mixture but the model has some difficulties to correlate correctly the region close to the critical point. Moreover, some deviations are observed for the vapour composition.

Figure 5 shows the evolution of the relative volatility for the measured temperatures as a function of ethane composition. A very good agreement between the experimental relative volatility and the calculated values using PR EoS can be observed. Similar to PR EoS (model 1), NRTL calculations (model 2) are found adequate for the purpose of this work. Figures 6 and 7 show the evolution of BIP with temperature for both models.

In order to quantify the quality of the fit of PR EoS to the experimental data, the mean relative absolute percentage deviations (MRD) and the bias on liquid and vapour mole fractions were calculated. They are all listed in Table 7 . The expressions of MRD and bias are defined by Eqs. (5) and (6) as follows:

$$
\begin{gathered}
\operatorname{MRD}(\mathrm{U})=\frac{100}{N} \sum\left[\left|\frac{U_{c a l}-U_{\text {exp }}}{U_{\text {exp }}}\right|\right] \\
\operatorname{bias}(\mathrm{U})=\frac{100}{N} \sum\left[\frac{U_{c a l}-U_{\text {exp }}}{U_{\text {exp }}}\right]
\end{gathered}
$$

where $\mathrm{U}$ represents $\mathrm{x}_{1}$ or $\mathrm{y}_{1}$ and $\mathrm{N}$ is the number of data points; we repeated each compositional analysis for 8 representative samples at each point. 


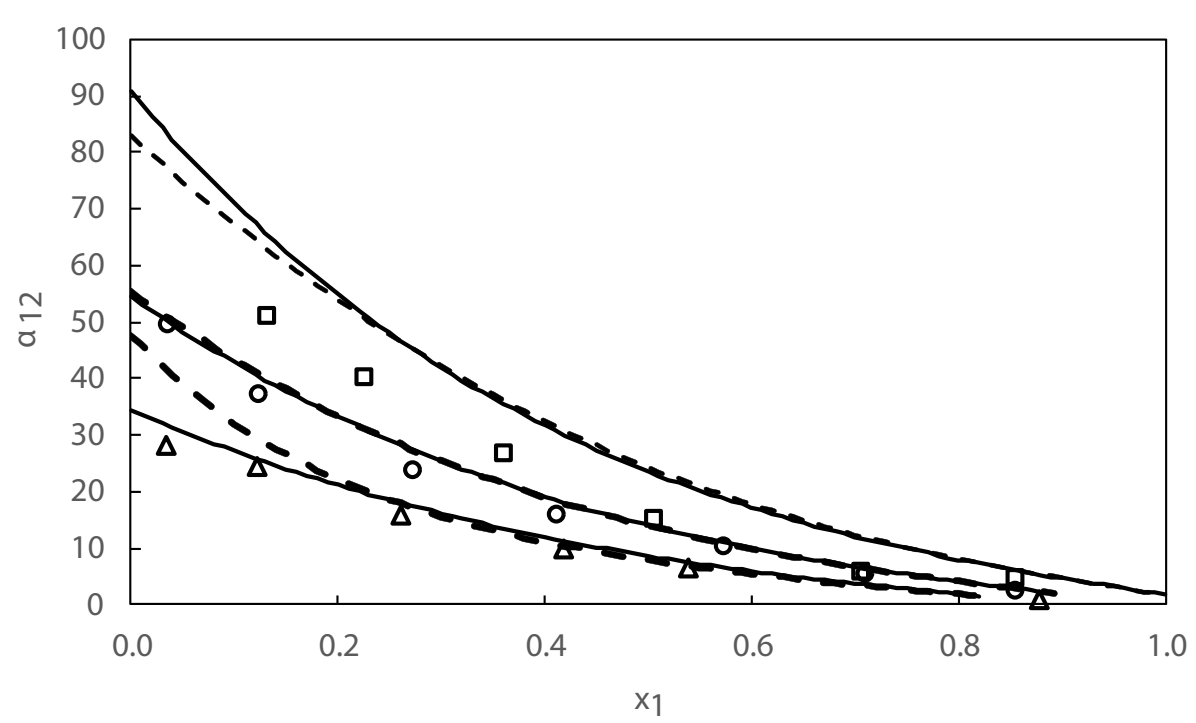

Figure 5 Relative volatility for (ethane + ethyl mercaptan) system. Points are experimental data at three isotherms: $\square 303 \mathrm{~K} ; \circ 323 ; \Delta 343 \mathrm{~K}$. Solid Lines are calculations using Model 1, dashed lines are calculations using Model 2.

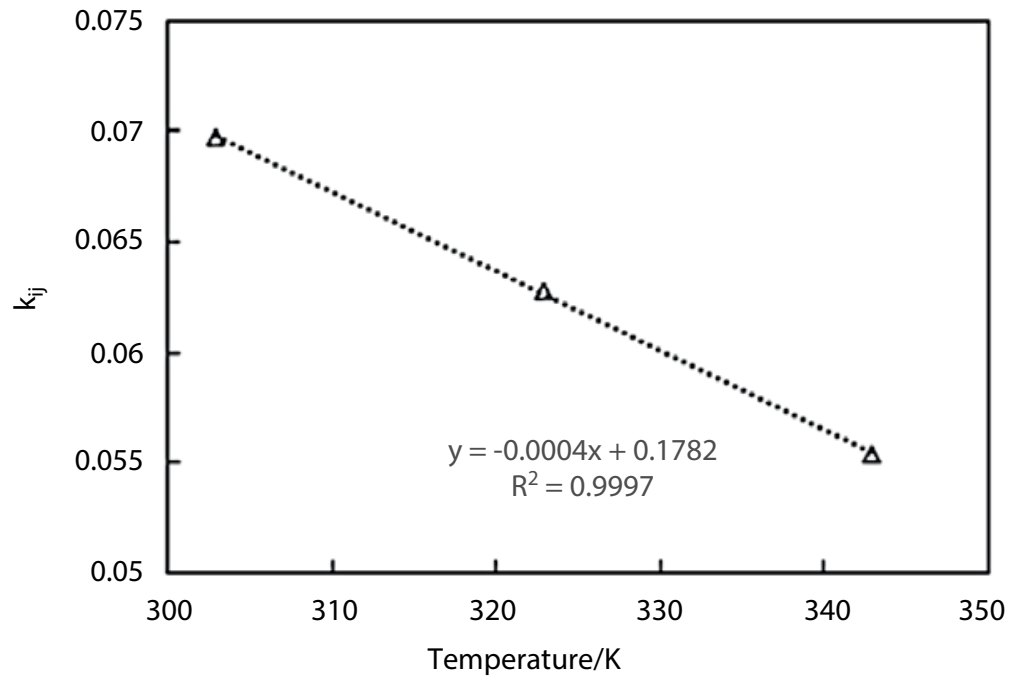

Figure 6 Temperature-dependent binary interaction parameter regressed over the experimental data. 


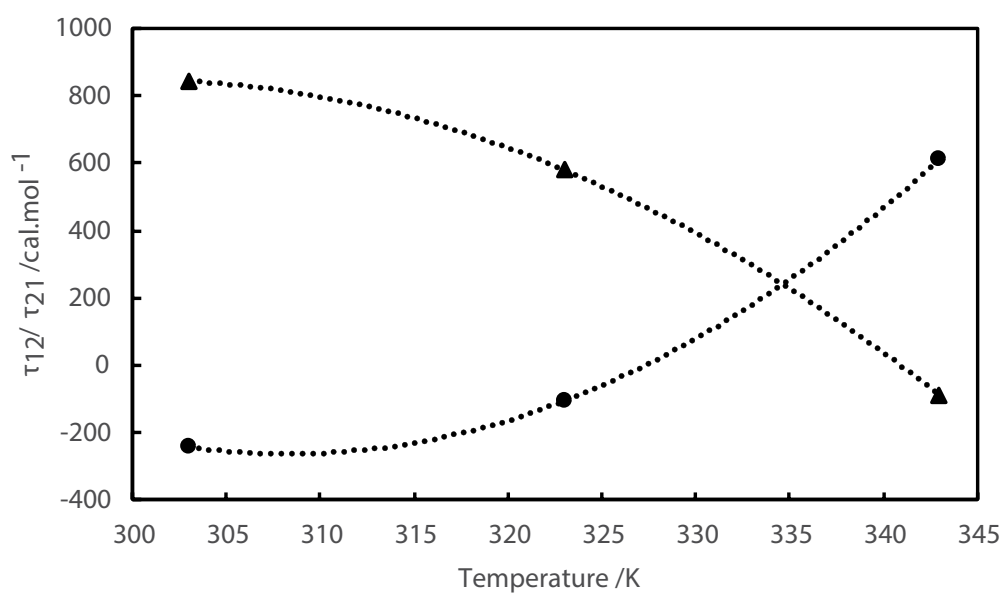

Figure 7 Temperature-dependent NRTL binary interaction parameter regressed over the experimental data $(\boldsymbol{\Delta})$ : a12, $(\bullet)$ : a21. Dotted lines: tendency curves.

Table 7 MRD and Bias values for liquid and vapour phase compositions.

\begin{tabular}{|l|c|c|c|c|}
\hline T/K & Bias (x)/\% & MRD(x)/\% & Bias(y)/\% & MRD(y)/\% \\
\hline \multicolumn{5}{|l|}{ Model 1 (PR EoS) } \\
\hline 303 & -0.5 & 2.5 & -2.1 & 2.1 \\
\hline 323 & -3.2 & 4.3 & -1.7 & 1.7 \\
\hline 343 & -3.3 & 7.4 & -3.8 & 3.8 \\
\hline Model 2 (NRTL) & \multicolumn{5}{|l|}{} \\
\hline 303 & -1.7 & 3.4 & -2.2 & 2.2 \\
\hline 323 & -2.7 & 3.8 & -1.7 & 1.7 \\
\hline 343 & 6.5 & 9.1 & -3.0 & 3.0 \\
\hline
\end{tabular}

\section{Conclusion}

In this paper, new VLE data of the (ethane + ethanethiol) binary system are presented. Experimental measurements were performed at three isotherms using a sapphire-tube cell under static conditions with online sampling and phase analysis using a GC-TCD. The uncertainties are $0.03 \mathrm{~K}$ for temperature, $0.4 \mathrm{kPa}$ for pressure and 0.0043 for phase compositions in mole fraction. The experimental data were correlated using PR EoS combined with the classical van der Waals mixing rules and with NRTL model both showing adequacy. This system can be classified as a 
type I or type II according to Scott and van Konynenburg [15] classification. With increase of impurities such as organic sulphur species in hydrocarbon resources, this work is very important as it's extremely difficult to work with these species due to safety issues.

\section{Acknowledgements}

We acknowledge the Scottish Funding Council for providing a travel grant to Dr Waheed Afzal under Northern Research Partnership program. Mr Pascal Theveneau is gratefully acknowledged for his support to adopt experimental setup for this work.

\section{References}

1. W. Afzal, Phase Equilibria of Glycol-Natural Gas Systems. Ph.D. Dissertation, Ecole des Mines de Paris (2009).

2. W. Afzal, M.P. Breil, I. Tsivintzelis, A.H. Mohammadi, G.M. Kontogeorgis, and D. Richon, Experimental study and phase equilibrium modeling of systems containing acid gas and glycol. Fluid Phase Equilibr. 318, 40-50 (2012).

3. W. Afzal and J.M. Prausnitz, Four methods for measuring the solubilities of gases and vapors in liquids and polymers. Вестник Санкт-Петербургского университета. Серия 4. Физика. Химия 1; the manuscript is published in English (2013).

4. W. Afzal, A.H. Mohammadi, and D. Richon, Solubility study of certain sulfur species in glycol aqueous solutions (GPA 992-3): experimental vapor-liquid equilibrium data for $\left(\mathrm{COS} / \mathrm{H}_{2} \mathrm{~S} / \mathrm{MEG} / \mathrm{H}_{2} \mathrm{O}\right)$ and $\left(\mathrm{COS} / \mathrm{H}_{2} \mathrm{~S} / \mathrm{TEG} / \mathrm{H}_{2} \mathrm{O}\right)$ systems. Gas Processors Association Research Report 204, Tulsa, OK (2008).

5. W. Afzal, M.P. Breil, P. Théveneau, A.H. Mohammadi, G.M. Kontogeorgis, and D. Richon, Phase equilibria of mixtures containing glycol and n-alkane: experimental study of infinite dilution activity coefficients and modeling using the cubic-plus-association equation of state. Ind. Eng. Chem. Res. 48(24), 11202-11210 (2009).

6. J.A. Awan, K. Thomsen, C. Coquelet, P.L. Fosbøl, and D. Richon, Vapor- liquid equilibrium measurements and modeling of the propyl mercaptan+ methane+ water system. J. Chem. Eng. Data. 55(2), 842-846 (2009).

7. A.G. Perez, A. Valtz, C. Coquelet, P. Paricaud, and A. Chapoy, Experimental and modelling study of the densities of the hydrogen sulphide+ methane mixtures at 253, 273 and $293 \mathrm{~K}$ and pressures up to $30 \mathrm{MPa}$. Fluid Phase Equilibr. 427, 371-383 (2016).

8. J.A. Awan, I. Tsivintzelis, M.P. Breil, C. Coquelet, D. Richon, and G.M. Kontogeorgis, Phase equilibria of mixtures containing Organic Sulfur Species (OSS) and water/hydrocarbons: VLE measurements and modeling using the cubic-plus-association equation of state. Ind. Eng. Chem. Res. 49(24), 12718-12725 (2010).

9. C. Coquelet, S. Laurens, and D. Richon, Measurement through a Gas Stripping Technique of Henry's Law Constants and Infinite Dilution Activity Coefficients of Propyl Mercaptan, Butyl Mercaptan, and Dimethyl Sulfide in Methyldiethanolamine (1)+ Water (2) with w 1= 0.25 and 0.35. J. Chem. Eng. Data. 53(11), 2540-2543 (2008).

10. R.M. Zin, C. Coquelet, A. Valtz, M.I. Abdul Mutalib, and K.M. Sabil, Measurement of Henry's Law constant and infinite dilution activity coefficient of isopropyl mercaptan 
and isobutyl mercaptan in (methyldiethanolamine (1)+ water (2)) with $\mathrm{w} 1=0.25$ and 0.50 at temperature of (298 to 348) $\mathrm{K}$ using inert gas stripping method. J. Chem. Thermodyn. 93, 193-199 (2016).

11. D-Y. Peng and D.B. Robinson, A new two-constant equation of state. Ind. Eng. Chem. Fund. 15(1), 59-64 (1976).

12. M.L. Michelsen, A modified Huron-Vidal mixing rule for cubic equations of state. Fluid Phase Equilibr. 60(1-2), 213-219 (1990).

13. H. Renon and J.M. Prausnitz, Local compositions in thermodynamic excess functions for liquid mixtures. AIChE J. 14(1), 135-144 (1968).

14. O. Baudouin, S. Dechelotte, P. Guittard, and A.Vacher, Simulis Thermodynamics: an open framework for users and developers. Proceedings of 23rd European Symposium on Applied Thermodynamics, Cannes, France (2008).

15. R.L. Scott and P.H. van Konynenburg, Static properties of solutions. Van der Waals and related models for hydrocarbon mixtures. Discuss. Faraday Soc. 49, 87-97 (1970). 